\title{
Cough presentation and cough-related healthcare utilization in tertiary care: analysis of routinely collected academic institutional database
}

Jin An

University of Ulsan College of Medicine

Ji-Hyang Lee

University of Ulsan College of Medicine

Ha-Kyeong Won

University of Ulsan College of Medicine

Yewon Kang

University of Ulsan College of Medicine

Hyouk-Soo Kwon

University of Ulsan College of Medicine

Jae-Seung Lee

University of Ulsan College of Medicine

Sei Won Lee

University of Ulsan College of Medicine

Tae-Bum Kim

University of Ulsan College of Medicine

Yeon-Mok Oh

University of Ulsan College of Medicine

You Sook Cho

University of Ulsan College of Medicine

Sang-Do Lee

University of Ulsan College of Medicine

Hee-Bom Moon

University of Ulsan College of Medicine

Woo-Jung Song ( $\sim$ swj0126@amc.seoul.kr)

University of Ulsan College of Medicine

\section{Research Article}

Keywords: cough, electronic health record, epidemiology 
Posted Date: May 18th, 2022

DOI: https://doi.org/10.21203/rs.3.rs-1341403/v2

License: (c) (i) This work is licensed under a Creative Commons Attribution 4.0 International License. Read Full License 


\section{Abstract}

Purpose: Routinely collected data (RCD) from electronic health records (EHR) are useful for studying disease epidemiology in the real world. We examined cough presentation and cough-related healthcare utilization using an academic institutional EHR database in Korea.

Methods: This is a retrospective cohort study of patients with subacute (3-8 weeks) or chronic cough ( $>8$ weeks in duration) referred to allergy and asthma clinics. Cases were identified using the search of the chief complaint in the data fields. Structured data were analyzed, including demographics, medical history, symptoms, and diagnostic tests. Healthcare utilization for 1 year was assessed for drug prescriptions, additional tests, or outpatient visits.

Results: Among 28,312 new referrals for 8 years, cough was the chief complaint in 13,223 cases (46.7\%); 3,810 subacute and 7,150 chronic cough patients were analyzed. Common demographic profile was middle-aged woman (mean age 52.1 years, and female 63\%). Cough was frequently accompanied by anterior nasal (about 50\%), lower airway (30\%), or acid reflux disease symptoms $(20 \%)$, and by test abnormalities in chest X-rays (14\%), spirometry (23\%), or T2 inflammation markers (40\%). Chronic cough patients frequently required additional tests (chest CT scan: $24 \%$ ), drug prescriptions (codeine: $21.5 \%$ and oral steroids: $9.9 \%$, and long-term healthcare utilization (16.0\%) for 1 year.

Conclusions: This RCD analysis suggests that cough is a common chief complaint at allergy and asthma clinics, but the clinical presentation may be heterogeneous. Further studies are needed to understand long-term outcomes and reduce the disease burden.

\section{Introduction}

Cough is an essential airway defense mechanism but also one of frequent symptoms for which patients seek medical consultation [1]. In particular, chronic cough is a clinically important condition, with high population prevalence and substantial impact on patient quality of life [2-4].

Most current knowledge on cough epidemiology has been obtained from large-scale general populations using simple questionnaire surveys, or small focused studies of patients visiting specialist cough clinics. Routinely collected data (RCD) from electronic health records (EHRs) or health administrative data contain comprehensive data, including records of health services, medical procedures, prescriptions, and diagnoses, and may offer useful sources for studying disease epidemiology in the real world [5]. However, due to the lack of a diagnostic code for chronic cough in the International Classification of Diseases (ICD)-9 or ICD-10 systems [6], the use of RCD has been very limited in cough research.

Considering this background, this study investigated cough presentation and cough-related healthcare utilization using an academic institutional EHR database of a tertiary hospital in Seoul, Korea. The institutional EHR database has a risk of selection bias (as it may consist of more severe cases than primary or secondary clinics) but has strength in case identification, longitudinal structured data 
collection, and analysis of prescriptions and diagnostic tests in a large scale. Using the database, we constructed a retrospective cohort of patients with subacute and chronic cough and analyzed their clinical characteristics and healthcare utilization during the first year of management.

\section{Materials And Methods}

\section{Study population}

This retrospective cohort analysis reviewed the tertiary institutional EHR of patients with subacute or chronic cough referred to allergy and asthma clinics, routinely collected between January 2010 and August 2018. A structured case report form (CRF) has been used to collect baseline information of every new referral. This form includes the chief complaint and duration, present illness, concomitant symptoms, past medical history, and demographics. The CRF was routinely filled by specialist nurses and physicians (allergists or pulmonologists) at the clinics.

Target populations were newly referred patients with subacute (3-8 weeks in duration) or chronic cough (> 8 weeks in duration) $[7,8]$. Cough cases were first identified using the text search for the chief complaint indicating "cough" or "coughing" (either in English or Korean) in the EHR data field. Then, the data field for the duration of the chief complaint was retrieved to verify cases with subacute or chronic cough. For subsequent analyses, subjects were excluded if 1) cough duration was missing, 2) duration was less than 3 weeks, or 3 ) other symptoms, such as hemoptysis, fever, chest discomfort, or pain, were indicated as co-chief complaints. Study population selection is presented in Fig. 1A. Structured data collected during the first year were retrieved for analysis of healthcare utilization (Fig. 1B). The study protocol was approved by the hospital institutional review board (IRB No. 2019 - 0511).

\section{Baseline clinical information}

Baseline parameters were retrieved from the structured EHR data. A total of 12 concurrent symptoms were routinely recorded in a dichotomous fashion (yes or no), including sputum, rhinorrhea, nasal obstruction, sneeze, postnasal drip (PND)/throat clearing, abnormal throat sensation (globus, tickling, or dryness), hoarseness, throat pain, dyspnea, wheeze, heartburn, and acid regurgitation. Cigarette smoking was classified into never, former, or current. A physician-diagnosed history defined past medical history. It included allergic rhinitis, chronic rhinosinusitis, asthma, COPD, bronchiectasis, pulmonary tuberculosis, interstitial lung disease (ILD), gastroesophageal reflux disease (GERD), heart failure, malignancy, hypertension, and diabetes mellitus (DM). The current use of an angiotensin-converting enzyme inhibitor (ACEi) was also recorded.

We retrieved the information of baseline diagnostic workups if conducted: chest X-rays, spirometry (and/or bronchodilator testing), and T2 marker tests (such as induced sputum eosinophils, blood eosinophils, or fractional exhaled nitric oxide [FeNO]). For analytic purpose, we used the following definitions: (1) chest X-rays were defined as abnormal if the patient had bronchiectasis, tuberculosis, 
malignancy, or any other grossly abnormal parenchymal lesion in the radiologist's formal interpretation; (2) airflow obstruction was defined as positive if the ratio of forced expiratory volume in 1 second (FEV1)/forced vital capacity (FVC) was less than 0.7 [9]; and (3) T2 inflammation marker was defined as positive if induced sputum eosinophils $\geq 3 \%$, a blood eosinophil count $\geq 300 \mathrm{cells} / \mu \mathrm{l}$, or FeNO level $\geq 30$ $\mathrm{ppb}[8]$.

\section{Healthcare utilization during the first year of management}

Healthcare utilization was assessed during the first year since the index date (baseline visit). It included additional diagnostic workups, prescribed medications, and the number of outpatient visits and hospitalizations. We retrieved the information of additional diagnostic tests if prescribed by specialist physicians at the clinics: methacholine bronchial challenge test, nasal endoscopy, laryngoscopy, and chest computed tomography (CT) scan.

Drug records were retrieved for the following prescriptions: inhaled bronchodilators, inhaled corticosteroids (ICS), anti-leukotrienes, $\mathrm{H} 1$-antihistamines, pseudoephedrine, proton pump inhibitors (PPIs), codeine (or codeine-containing drugs), amitriptyline, gabapentin, pregabalin, antibiotics, and oral corticosteroids (OCS). Drug exposure was defined as positive if a drug or drugs were prescribed at least once during the first year since the index date. In the case of OCS, cumulative dose (prednisolone equivalent) was also calculated, as the risk of complications may increase in a dose-dependent manner [10].

To quantify the proportion of patients who need repeated outpatient visits over a period, we arbitrarily defined "long-term healthcare utilization" by using the number and timing of subsequent outpatient visits during the first 1 year. It was defined positive if a patient had one or more outpatient visits during the first 6 months since the baseline visit and had at least one more visit during the next 6 months (Supplementary Figure S1 in Online Repository). The definition is based on our usual clinical practice pattern.

\section{Statistical analysis}

Descriptive data were calculated as mean \pm standard deviation, median with, or percentages, depending on the type of distribution of each parameter. Group differences (subacute vs. chronic cough) were assessed using t-tests or chi-square tests. Multiple correspondence analyses were used to visualize and explore inter-relationships between concomitant symptoms. All calculations were performed with Stata 15.1 software (Stata Corp, College Station, TX, USA). A two-sided $p$-value $<0.05$ was considered statistically significant. The jvenn was used to draw a Venn diagram (http://jvenn.toulouse.inra.fr/app/example.html).

\section{Results}

\section{Study population}


From a total of 28,312 new referrals to the clinics between January 2010 and August 2018, cough was the chief complaint in 13,223 patients $(46.7 \%)$. Total of 10,960 subjects $(3,810$ subacute cough and 7,150 chronic cough) were included in the cohort for analysis (Fig. 1A). Patients were excluded for the following reasons: cough duration was missing $(n=20)$ or was less than 3 weeks $(n=827)$, or if patients had cochief complaints, such as hemoptysis, fever, chest discomfort or pain $(n=1,416)$. The distribution of cough duration is presented as a histogram in Fig. 2.

\section{Baseline characteristics}

Baseline demographic and clinical characteristics were compared between subacute and chronic cough patients (Table 1). Cough duration was median 1 month (IQR: 0.8 to 1 month) in subacute cough and median 6 months (IQR: 3 to 30 months) in chronic cough patients. Women commonly predominated in both patient groups. Patients with chronic cough were significantly older than those with subacute cough $(52.9 \pm 15.6$ vs. $50.5 \pm 15.9$ years; $p<0.001)$. Patients with chronic cough had more physician-diagnosed histories of respiratory or non-respiratory diseases, such as allergic rhinitis, asthma, COPD, ILD, GERD, hypertension, or DM. 
Table 1

Baseline characteristics of study participants

\begin{tabular}{|c|c|c|c|}
\hline Characteristic & $\begin{array}{l}\text { Subacute cough } \\
(n=3,810)\end{array}$ & $\begin{array}{l}\text { Chronic cough } \\
(n=7,150)\end{array}$ & $P$-value \\
\hline Cough duration (months) & Median 1 (IQR: 0.8-1) & Median 6 (IQR: 3-30) & $<0.001$ \\
\hline Age (years) & $50.5 \pm 15.9$ & $52.9 \pm 15.6$ & $<0.001$ \\
\hline Gender, female, \% & 62.5 & 63.6 & 0.243 \\
\hline Smoking history, \% & & & 0.487 \\
\hline Never smoker & 71.0 & 71.6 & \\
\hline Former smoker & 21.0 & 20.1 & \\
\hline Current smoker & 8.0 & 8.3 & \\
\hline Use of ACE inhibitor, \% & 0.3 & 0.4 & 0.389 \\
\hline \multicolumn{4}{|c|}{ Physician-diagnosed history ever } \\
\hline \multicolumn{4}{|l|}{ Respiratory disease, \% } \\
\hline Allergic rhinitis & 10.5 & 11.8 & 0.049 \\
\hline Chronic rhinosinusitis & 19.8 & 18.8 & 0.008 \\
\hline Asthma & 14.8 & 21.7 & $<0.001$ \\
\hline COPD & 1.1 & 2.0 & $<0.001$ \\
\hline Bronchiectasis & 0.3 & 0.5 & 0.263 \\
\hline Pulmonary tuberculosis & 0.2 & 0.3 & 0.138 \\
\hline ILD & 0.2 & 0.5 & 0.021 \\
\hline \multicolumn{4}{|l|}{ Non-respiratory disease, \% } \\
\hline GERD & 7.0 & 10.1 & $<0.001$ \\
\hline Malignancy & 8.0 & 7.8 & 0.618 \\
\hline Heart failure & 0.5 & 0.4 & 0.771 \\
\hline Hypertension & 19.3 & 21.5 & $<0.001$ \\
\hline DM & 7.0 & 8.8 & 0.001 \\
\hline
\end{tabular}


Among 12 concomitant symptoms recorded at baseline, patients with subacute and chronic cough had a median three accompanying symptoms (IQR: 2-5). An abnormal throat sensation was the most frequent (about 70\%) in both groups. However, patients with chronic cough had significantly more sneeze, dyspnea, wheeze, heartburn, and acid regurgitation but had less PND/throat clearing, sputum production, hoarseness, and throat pain than those with subacute cough (Table 2).

Table 2

Concomitant symptoms

\begin{tabular}{|llll|}
\hline Symptom (\%) & $\begin{array}{l}\text { Subacute cough } \\
(\mathbf{n = 3 , 8 1 0 )}\end{array}$ & $\begin{array}{l}\text { Chronic cough } \\
(\mathbf{n}=\mathbf{7 , 1 5 0 )}\end{array}$ & P-value \\
\hline Abnormal Throat sensation* & 70.0 & 70.8 & 0.368 \\
\hline PND/throat clearing & 39.2 & 36.9 & 0.021 \\
\hline Rhinorrhea & 32.9 & 33.6 & 0.482 \\
\hline Sneeze & 24.2 & 30.8 & $<0.001$ \\
\hline Nasal obstruction & 25.0 & 25.8 & 0.358 \\
\hline Sputum production & 29.4 & 24.3 & $<0.001$ \\
\hline Dyspnea & 23.2 & 26.0 & $<0.001$ \\
\hline Wheeze & 15.4 & 19.0 & $<0.001$ \\
\hline Hoarseness & 15.9 & 11.9 & $<0.001$ \\
\hline Throat pain & 14.7 & 10.6 & $<0.001$ \\
\hline Heartburn & 15.8 & 18.9 & $<0.001$ \\
\hline Acid regurgitation & 12.1 & 15.2 & $<0.001$ \\
\hline PND, post-nasal drip & & & \\
\hline *Globus, tickling, or dryness. & & & \\
\hline
\end{tabular}

In multiple correspondence analyses, symptom co-localization pattern was similar to anatomic locations of the symptoms (Fig. 3A). The localization of the symptoms suggestive of acid reflux disease, such as heartburn and acid regurgitation, was distinct from nasal, lower airway, or throat symptoms. Symptom co-localization patterns between chronic cough and subacute cough patients were not different (data not presented).

Based on the anatomic locations and co-occurrence patterns, major symptoms were classified into anterior nasal (rhinorrhea, sneezing, or nasal obstruction), lower airway (dyspnea or wheeze), and acid reflux (heartburn or acid regurgitation). Anterior nasal symptoms were most common in patients with subacute and chronic cough (48.9\% and $51.8 \%$, respectively), followed by lower airway $(30.2 \%$ and $33.6 \%$, 
respectively) and acid reflux symptoms ( $21.3 \%$ and $25.8 \%$, respectively). A total of $28.0 \%$ of subacute cough and $32.5 \%$ of chronic cough patients had multiple symptoms. However, $32.9 \%$ of subacute cough and $28.9 \%$ of chronic cough had none of these symptoms (Fig. 3B and 3C).

\section{Baseline diagnostic work-up}

The number of patients who underwent baseline diagnostic work-up and their test results are summarized in Table 3 and Fig. 4, respectively. Chest X-rays were performed in $83.6 \%$ of patients during the first month, and about $13.8 \%$ of subacute cough and $14.8 \%$ of chronic cough patients had abnormal findings. Spirometry was significantly more frequently conducted, and airflow obstruction was also more positive in chronic cough than in subacute cough patients (56.5\% vs. $42.7 \%$ in Table 3 ; and $12.8 \%$ vs.

$9.7 \%$ in Fig. 4, respectively). T2 inflammation marker testing was done in $31.5 \%$ of subacute cough and $39.9 \%$ of chronic cough patients (Table 3 ). Sputum eosinophilia ( $\geq 3 \%$ ) and blood eosinophilia ( $\geq 300$ cells/uL) were significantly more frequent in chronic cough patients. The proportion of FeNO $\geq 30 \mathrm{ppb}$ did not differ between subacute and chronic cough patients (Fig. 4). 
Table 3

Healthcare utilization during the first year

\begin{tabular}{|c|c|c|c|}
\hline & $\begin{array}{l}\text { Subacute } \\
\text { cough }(n= \\
3,810)\end{array}$ & $\begin{array}{l}\text { Chronic } \\
\text { cough }(n= \\
7,150)\end{array}$ & $P$-value \\
\hline \multicolumn{4}{|l|}{ Baseline diagnostic tests, $\mathrm{n}$ (of total population, \%) } \\
\hline Chest X-ray & $3,243(85.1)$ & $5,923(82.8)$ & 0.002 \\
\hline Spirometry & $1,628(42.7)$ & $4,037(56.5)$ & $<0.001$ \\
\hline Bronchodilator test & $847(22.2)$ & $2,128(29.8)$ & $<0.001$ \\
\hline Induced sputum eosinophils & $564(14.8)$ & $1,646(23.0)$ & $<0.001$ \\
\hline Blood eosinophil count & $737(19.3)$ & $1,553(21.7)$ & 0.004 \\
\hline FeNO test & $102(2.7)$ & $253(3.5)$ & 0.015 \\
\hline $\begin{array}{l}\text { Any T2 inflammation marker (at least one of induced } \\
\text { sputum, blood eosinophils, or FeNO test) }\end{array}$ & $1,200(31.5)$ & $2,851(39.9)$ & $<0.001$ \\
\hline \multicolumn{4}{|l|}{ Additional diagnostic tests, $\mathrm{n}$ (of total population, \%) } \\
\hline Nasal endoscopy & $1,647(43.2)$ & $4,174(56.6)$ & $<0.001$ \\
\hline Laryngoscopy & $1,373(36.0)$ & $3,569(49.9)$ & $<0.001$ \\
\hline Methacholine bronchial challenge test & $808(21.2)$ & $1,996(27.9)$ & $<0.001$ \\
\hline Chest CT scan & $823(21.6)$ & $1,716(24)$ & 0.005 \\
\hline \multicolumn{4}{|l|}{ Drugs, any exposure, $\mathrm{n}$ (\% of total) } \\
\hline \multicolumn{4}{|l|}{ Respiratory (oral or inhaled) } \\
\hline ICS & $473(12.4)$ & $1,374(19.2)$ & $<0.001$ \\
\hline SABA & $79(2.0)$ & $192(2.7)$ & 0.10 \\
\hline LABA & $348(9.1)$ & $1,005(14.1)$ & $<0.001$ \\
\hline LAMA & $71(1.9)$ & $225(3.2)$ & $<0.001$ \\
\hline Oral anti-leukotrienes & $468(12.3)$ & $1,265(17.7)$ & $<0.001$ \\
\hline Oral $\mathrm{H} 1$-antihistamines & $1,505(39.5)$ & $3,637(50.9)$ & $<0.001$ \\
\hline
\end{tabular}

FeNO, fractional exhaled nitric oxide; CT, computed tomography; ICS, inhaled corticosteroid; SABA, short-acting beta2-agonist; LABA, long-acting beta2-agonist; LAMA, long-acting muscarinic antagonist.

*Long-term healthcare utilization was defined positive if a patient had one or more outpatient visits during the first 6 months since the baseline visit and also had at least one more visit during the next 6 months. 


\begin{tabular}{|c|c|c|c|}
\hline & $\begin{array}{l}\text { Subacute } \\
\text { cough }(n= \\
3,810)\end{array}$ & $\begin{array}{l}\text { Chronic } \\
\text { cough }(n= \\
7,150)\end{array}$ & $P$-value \\
\hline Oral pseudoephedrine & $904(23.7)$ & $2,104(29.4)$ & $<0.001$ \\
\hline \multicolumn{4}{|l|}{ Gastrointestinal (oral) } \\
\hline Proton pump inhibitors & $567(14.9)$ & $1,732(24.2 \%)$ & $<0.001$ \\
\hline \multicolumn{4}{|l|}{ Narcotics/neuromodulators (oral) } \\
\hline Codeine-containing drugs & $699(18.3)$ & $1,539(21.5)$ & $<0.001$ \\
\hline Amitriptyline & $18(0.5)$ & $84(1.2)$ & $<0.001$ \\
\hline Gabapentin or pregabalin & $20(0.5)$ & $131(1.8)$ & $<0.001$ \\
\hline \multicolumn{4}{|l|}{ Miscellaneous (oral) } \\
\hline Antibiotics & $907(23.8)$ & $1,691(23.7)$ & 0.855 \\
\hline Corticosteroids & $251(6.6)$ & $704(9.9)$ & $<0.001$ \\
\hline Cumulative dose (mg, prednisolone equivalent) & $\begin{array}{l}\text { Median } 35 \\
\text { (IQR: } 25-40)\end{array}$ & $\begin{array}{l}\text { Median } 35 \\
\text { (IQR: 25-70) }\end{array}$ & $<0.001$ \\
\hline $\begin{array}{l}\text { Number of subsequent outpatient visits after baseline } \\
\text { visit (\%) }\end{array}$ & & & $<0.001$ \\
\hline $1-3$ & 61.1 & 62.8 & \\
\hline $4-6$ & 10.2 & 17.4 & \\
\hline$\geq 7$ & 3.1 & 6.2 & \\
\hline Hospitalization $\geq 1$ (\%) & 0.4 & 0.5 & 0.75 \\
\hline Long-term healthcare utilization (\%)* & 8.2 & 16.0 & $<0.001$ \\
\hline \multicolumn{4}{|c|}{$\begin{array}{l}\text { FeNO, fractional exhaled nitric oxide; CT, computed tomography; ICS, inhaled corticosteroid; SABA, } \\
\text { short-acting beta2-agonist; LABA, long-acting beta2-agonist; LAMA, long-acting muscarinic } \\
\text { antagonist. }\end{array}$} \\
\hline \multicolumn{4}{|c|}{$\begin{array}{l}\text { *Long-term healthcare utilization was defined positive if a patient had one or more outpatient visits } \\
\text { during the first } 6 \text { months since the baseline visit and also had at least one more visit during the next } 6 \\
\text { months. }\end{array}$} \\
\hline
\end{tabular}

\section{Healthcare utilization during the first year of management}

Healthcare utilization is summarized in Table 3. The number of patients who underwent nasal endoscopy, laryngoscopy, methacholine challenge, or chest CT scan was higher in chronic cough than in the subacute cough group. Chest CT scans were performed in $23.2 \%$ of the study population; among 7,833 patients with normal chest X-rays at baseline, chest CT scans were done in $19.3 \%$. 
$\mathrm{H} 1$-antihistamines were the most common medications prescribed to subacute cough (39.5\%) and chronic cough patients (50.9\%; Table 3 ). They were followed by pseudoephedrine (27.4\%), antibiotics (23.7\%), PPIs (21.0\%), codeine-containing drugs (20.4\%), ICS (16.9\%), and anti-leukotrienes (15.8\%). Most medications were significantly prescribed more to chronic cough patients, except for antibiotics and inhaled short-acting beta2-agonists. OCS were given to $6.6 \%$ of subacute cough and $9.9 \%$ of chronic cough patients. One-year cumulative OCS doses were median $35 \mathrm{mg}$ (IQR: 25-70 mg, prednisolone equivalent) in chronic cough and $35 \mathrm{mg}(25-40 \mathrm{mg})$ in subacute cough patients, respectively $(p<0.001$; Fig. 5). The number of subsequent outpatient visits was significantly higher in chronic cough patients, but hospitalization did not differ. Long-term healthcare utilization was found in $16.0 \%$ of chronic cough and $8.2 \%$ of subacute cough patients $(p<0.001$; Table 3$)$.

\section{Discussion}

Using a large academic institutional EHR collected for 8 years, this study described the clinical characteristics and healthcare utilization of newly referred patients with subacute and chronic cough to the tertiary allergy and asthma clinics in Seoul, Korea. Cough was a common chief complaint, comprising a large proportion of all referrals to the clinics ( $46.7 \%$ of 28,312 referrals). In patients with either subacute or chronic cough, cough was frequently accompanied by anterior nasal (about 50\%), lower airway (30\%), or acid reflux symptoms (20\%), and also by test abnormalities in chest X-rays, spirometry, or T2 inflammation markers, indicating the heterogeneity of clinical presentation of subacute and chronic cough patients visiting allergy and asthma clinics.

It has been conceived that cough is one of the most common reasons why patients seek medical care [11]. However, comprehensive large-scale data is scarce. In the US National Ambulatory Medical Care Survey, acute cough was a common reason for seeking outpatient consultation [12]. In the Asia-Pacific multicenter questionnaire survey of 5,250 allergic or respiratory patients, cough or coughing up phlegm was frequently reported as the main reason for the outpatient visit (23\%) [13]. However, the Asia-Pacific study [13] focused only on patients with an established diagnosis of allergic rhinitis, rhinosinusitis, asthma, or COPD. Both surveys $[13,12]$ lacked specific information on cough characteristics and coughrelated healthcare utilization. In this regard, our findings are a valuable addition to the literature, providing specific data on cough presentation and subsequent healthcare utilization in the real world.

Recent real-world studies from the US reported the disease burden in patients with chronic cough (vs. those without chronic cough), including increased healthcare resource utilization, outpatient visits, diagnostic tests, and treatment needs [14-16]. Our findings are generally in line with these [14-16]. We found a substantial proportion of patients who required additional diagnostic tests, drug treatments, and outpatient visits, among the new referrals. Codeine-containing drugs were given to $21.5 \%$ of patients with chronic cough, and oral antibiotics to $23.7 \%$ and OCS to $9.9 \%$; these drugs have potential concerns with overuse, side effects, complications, or antimicrobial resistance in the long term[11, 10]. Given their potential health risks, the medication uses and health consequences should be the outcomes of longterm follow-up studies of cough patients. 
It should be noted that subacute cough was the chief complaint in $34.8 \%$ of this tertiary care population, which was much higher than expected. This high proportion is likely attributed to the national healthcare systems in South Korea, which allow easy and rapid access to tertiary care hospitals even with a simple referral letter from a primary clinic [17], and the findings are presumably distinct from some countries with strict referral systems like the UK. Although lower than those with chronic cough, the proportion of subacute cough patients who required additional diagnostic tests (e.g., chest CT in $21.6 \%$ ) and drug treatments (codeine-containing drugs in $18.3 \%$, and OCS in $6.6 \%$ ) was considerable. These findings suggest large unmet clinical needs in patients with subacute cough as well.

Compared to previous small studies of Korean patients visiting specialist cough clinics $[18,19]$ or a recent clinical trial participant with refractory chronic cough [20], our study population were relatively younger (mean age 52.9 years) and less women (63.6\%) and had shorter cough duration (median 6 months). A major reason for the differences, we suppose, is that the latter was derived from allergy and asthma clinics, while the formers were from specialist cough clinics. In this regard, the information presented here may represent the characteristics of chronic cough patients at more general allergist and pulmonologist clinics.

This study had several limitations. First, it is a tertiary institution-based analysis, and thus has limited external validity. Second, there is a risk of misclassification as the information on cough characteristics and history relied on patient reports collected during routine clinical practice. Also, cough-associated symptoms were recorded in a dichotomous manner. Third, tools to evaluate cough severity or impact on life were not included in the routine EHR data collection. Their inclusion would help to increase the utility of institutional RCD analyses. Fourth, our study did not evaluate unstructured, free-text data at follow up visits, and thus could not evaluate treatment responses. Finally, as our analyses were limited to an academic institutional EHR database, healthcare utilization outside the institution could not be evaluated. However, most limitations are intrinsic to the nature of institutional RCD analysis; and it has strengths in large sample size and detailed longitudinal data collection including cough-related prescriptions, diagnostic tests, and healthcare utilization.

In conclusion, cough was a common chief complaint among new referrals to tertiary allergy and asthma clinics. Patients with either subacute or chronic cough had frequent comorbidities and different accompanying symptoms, indicating the heterogeneity of clinical presentations. They frequently required additional diagnostic tests, drug treatments (including OCS and codeine), and outpatient visits, suggesting the disease burden and future health risk. Further studies are needed to understand long-term health outcomes and reduce the disease burden of cough.

\section{Declarations}

Acknowledgements: none

\section{Funding}


This study was supported in part by a research grant from Investigator-Initiated Studies Program of Merck Sharp \& Dohme Corp. The opinions expressed in this paper are those of the authors and do not necessarily represent those of Merck Sharp \& Dohme Corp.

\section{Competing interests}

The authors declare that they have no competing interests.

\section{Authors' contributions}

Each of the authors confirms that this manuscript has not been previously published and is not currently under consideration by any other journal. Additionally, all of the authors have approved the contents of this paper and have agreed to BMC pulmonary medicine journals submission policies. WJS contributed to the design of the study. JA performed the main analysis and wrote the original draft. JHL, HKW and YK assisted in the analysis and interpretation of the data. HSK, JSL, SWL, TBK, YMO, YSC, SDL and HBM prepared the data collection. All authors revised the manuscript.

\section{Ethics approval}

This study was performed in line with the principles of the Declaration of Helsinki. The study protocol was approved by the hospital institutional review board (IRB No. 2019-0511).

\section{Consent to participate}

Individual subject informed consent was waived due to the retrospective nature of the study and no prospective engagement with subjects or their legal guardians.

\section{References}

1. Dicpinigaitis PV (2015) Clinical perspective - cough: an unmet need. Curr Opin Pharmacol 22:24-28

2. Song WJ, Chang YS, Faruqi S, Kim JY, Kang MG, Kim S, Jo EJ, Kim MH, Plevkova J, Park HW, Cho SH, Morice AH (2015) The global epidemiology of chronic cough in adults: a systematic review and meta-analysis. Eur Respir J 45 (5):1479-1481

3. French CL, Irwin RS, Curley FJ, Krikorian CJ (1998) Impact of chronic cough on quality of life. Arch Intern Med 158 (15):1657-1661

4. Won HK, Lee JH, An J, Sohn KH, Kang MG, Kang SY, Morice AH, Cho SH, Song WJ (2020) Impact of Chronic Cough on Health-Related Quality of Life in the Korean Adult General Population: The Korean National Health and Nutrition Examination Survey 2010-2016. Allergy Asthma Immunol Res 12 (6):964-979

5. Rudrapatna VA, Butte AJ (2020) Opportunities and challenges in using real-world data for health care. The Journal of Clinical Investigation 130 (2):565-574 
6. McGarvey L, Gibson PG (2019) What is chronic cough? Terminology. The Journal of Allergy and Clinical Immunology: In Practice 7 (6):1711-1714

7. Irwin RS, French CL, Chang AB, Altman KW, Adams TM, Azoulay E, Barker AF, Birring SS, Blackhall F, Bolser DC (2018) Classification of cough as a symptom in adults and management algorithms: CHEST guideline and expert panel report. Chest 153 (1):196-209

8. Song DJ, Song WJ, Kwon JW et al. (2018) KAAACI Evidence-Based Clinical Practice Guidelines for Chronic Cough in Adults and Children in Korea. Allergy Asthma Immunol Res 10 (6):591-613

9. Vestbo J, Hurd SS, Agusti AG et al. (2013) Global strategy for the diagnosis, management, and prevention of chronic obstructive pulmonary disease: GOLD executive summary. Am J Respir Crit Care Med 187 (4):347-365

10. Dalal AA, Duh MS, Gozalo L, Robitaille M-N, Albers F, Yancey S, Ortega H, Forshag M, Lin X, Lefebvre $P$ (2016) Dose-response relationship between long-term systemic corticosteroid use and related complications in patients with severe asthma. J Manag Care Spec Pharm 22 (7):833-847

11. Morice AH, Millqvist E, Bieksiene K et al. (2020) ERS guidelines on the diagnosis and treatment of chronic cough in adults and children. Eur Respir J 55 (1)

12. Cherry DK, Woodwell DA, Rechtsteiner EA (2007) National ambulatory medical care survey: 2005 summary.

13. Cho S-H, Lin H-C, Ghoshal AG, Bin Abdul Muttalif AR, Thanaviratananich S, Bagga S, Faruqi R, Sajjan $S$, Brnabic AJ, Dehle FC Respiratory disease in the Asia-Pacific region: Cough as a key symptom. In: Allergy \& Asthma Proceedings, 2016. vol 2.

14. Zeiger RS, Xie F, Schatz M, Hong BD, Weaver JP, Bali V, Schelfhout J, Chen W (2020) Prevalence and Characteristics of Chronic Cough in Adults Identified by Administrative Data. Perm J 24:1-3

15. Zeiger RS, Schatz M, Butler RK, Weaver JP, Bali V, Chen W (2020) Burden of Specialist-Diagnosed Chronic Cough in Adults. J Allergy Clin Immunol Pract 8 (5):1645-1657 e1647

16. Zeiger RS, Schatz M, Hong B, Li Q, Stern JA, Takhar HS, Weaver JP, Bali V, Schelfhout J, Chen W (2021) Patient-Reported Burden of Chronic Cough in a Managed Care Organization. J Allergy Clin Immunol Pract 9 (4):1624-1637 e1610

17. Kim AM, Cho S, Kim HJ, Jung H, Jo MW, Lee JY, Eun SJ (2018) Primary Care Patients' Preference for Hospitals over Clinics in Korea. Int J Environ Res Public Health 15 (6)

18. Won HK, Kang SY, Kang Y et al. (2019) Cough-Related Laryngeal Sensations and Triggers in Adults With Chronic Cough: Symptom Profile and Impact. Allergy Asthma Immunol Res 11 (5):622-631

19. Kang SY, Song WJ, Won HK, Chung SJ, Kim JY, Park HW, Morice AH, Cho SH (2020) Cough persistence in adults with chronic cough: A 4-year retrospective cohort study. Allergol Int 69 (4):588593

20. Morice AH, Birring SS, Smith JA, McGarvey LP, Schelfhout J, Martin Nguyen A, Xu ZJ, Wu WC, Muccino DR, Sher MR (2021) Characterization of Patients With Refractory or Unexplained Chronic Cough Participating in a Phase 2 Clinical Trial of the P2X3-Receptor Antagonist Gefapixant. Lung 199 (2):121-129 


\section{Figures}

\section{Figure 1}

Study algorithm. (A) Patient selection. (B) Study design. A total of 3,810 subacute cough and 7,150 chronic cough patients were included in this retrospective cohort (2010-2018). Baseline parameters including demographics and clinical information, and initial diagnostic work-ups were retrieved from case report forms collected at baseline visits. Healthcare utilizations were analyzed during the first 1 year since the baseline visit.

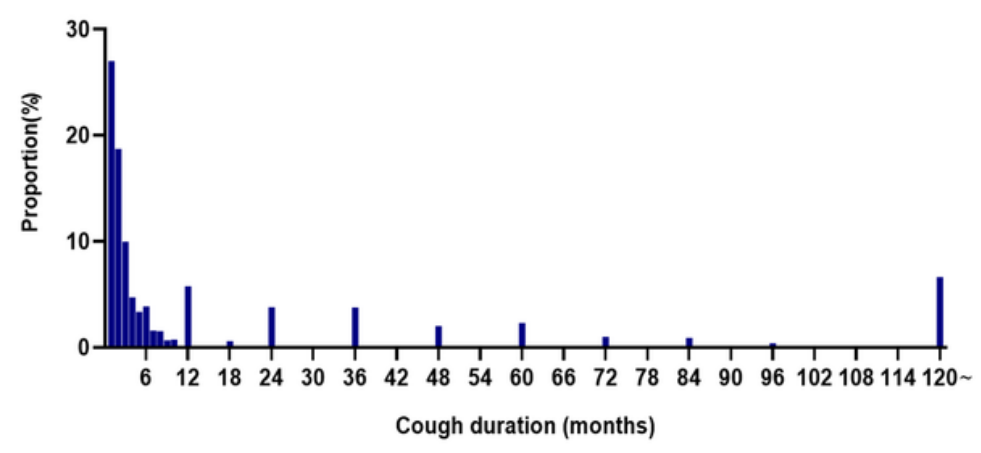

Figure 2

Cough duration in all patients referred with cough to the clinics between 2010-2018.

\section{Figure 3}

Symptom co-occurrence in patients with subacute and chronic cough. (A) Multiple correspondence plot for inter-relationships between concomitant symptoms ( $0=a b s e n c e ; 1=$ presence). (B) Venn diagram for anterior nasal (rhinorrhea, sneezing, or nasal obstruction), lower airway (dyspnea or wheeze), and acid 
reflux symptoms (heartburn or acid regurgitation) in patients with subacute cough. (C) Venn diagram for the symptoms in patients with chronic cough.

\section{Figure 4}

Baseline diagnostic evaluations: comparison of the findings between subacute and chronic cough. Chest X-ray was defined as abnormal if the patient had bronchiectasis, tuberculosis, malignancy, or any other grossly abnormal parenchymal lesion in the radiologist's formal interpretation. Bronchodilator response was defined positive by the increase in FEV1 by $12 \%$ - and $200-\mathrm{mL}$ post-bronchodilator inhalation. Abbreviations: CXR, chest X-ray; FEV1, forced expiratory volume in 1 second; FVC, forced volume capacity; FeNO, fractional exhaled nitric oxide. $P$ value; ns, not significant; ${ }^{*},<0.05$; and ${ }^{* *},<0.01$.

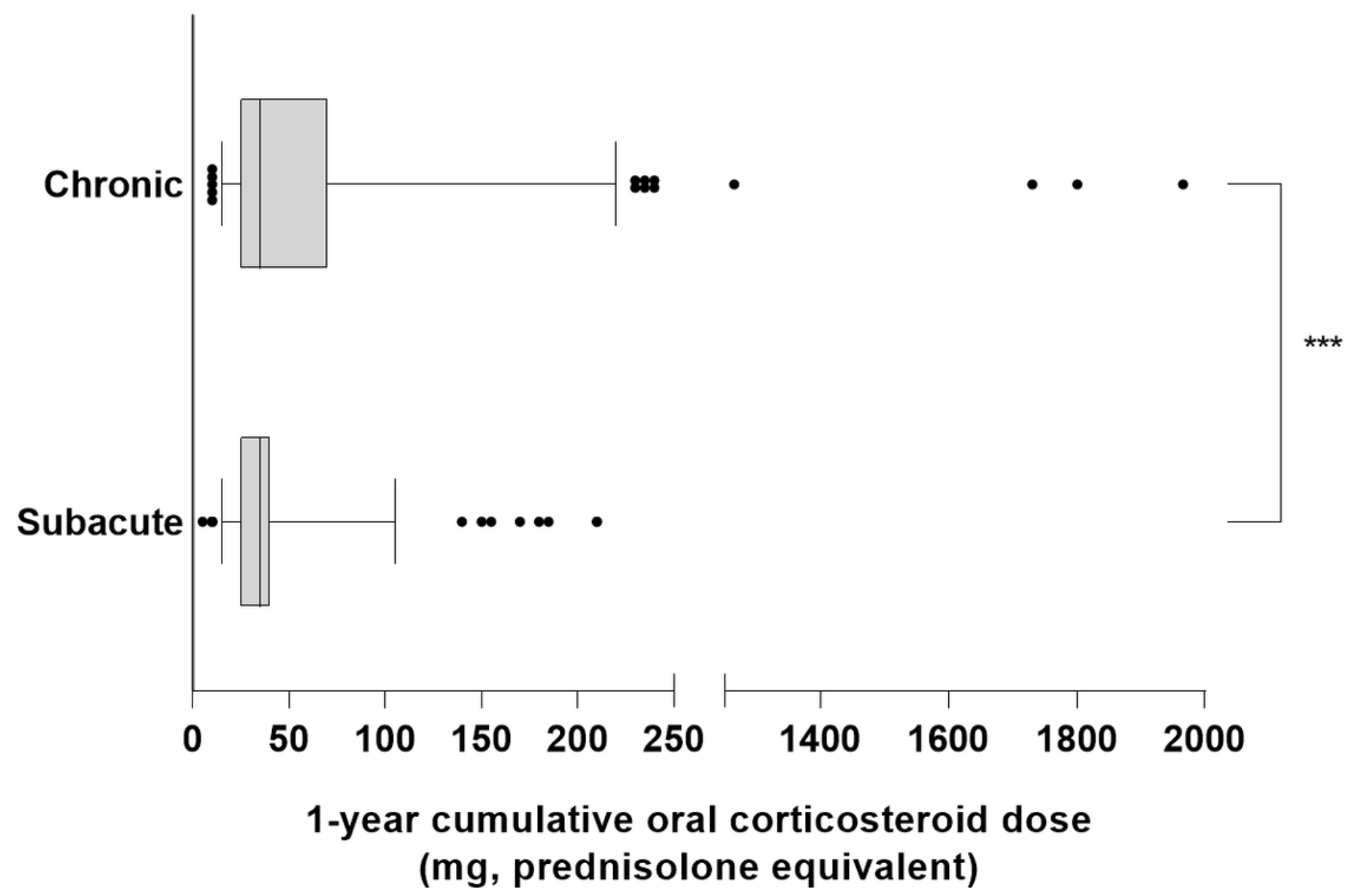

Figure 5

Box and whisker plots showing 1-year cumulative oral corticosteroid doses (prednisolone equivalent) in patients with subacute and chronic cough. The box indicates the lower and upper quartile; the whiskers 
mark the 5th and 95th percentiles, and values beyond these upper and lower bounds are considered outliers, marked with red dots. $P$ value; ${ }^{\star \star \star},<0.001$.

\section{Supplementary Files}

This is a list of supplementary files associated with this preprint. Click to download.

- OnlineRepository.docx 